\title{
Percepción de los enfermeros sobre seguridad del paciente en el servicio de emergencia: un estudio cualitativo
}

\section{Nurses' perceptions of patient safety in the emergency setting: a qualitative study}

\section{Percepção de enfermeiros sobre a segurança do paciente no ambiente de emergência: um estudo qualitativo}

Ana de Cássia da Ponte Portela ${ }^{1}$, Márcia Aline de Castro Olímpioº ${ }^{2}$ Michelle Alves Vasconcelos Ponte ${ }^{3}$, Francisco Diogenes dos Santos ${ }^{4}$, Alicequel Ferreira Gomes de Paiva ${ }^{5}$, Vanessa Emille Carvalho de Sousa ${ }^{6}$

${ }^{1}$ RN Specialist in Surgical Nursing, School of Nursing, Applied Theology Institute, cassiaponte34@gmail.com

${ }^{2} R N$ Specialist in Surgical Nursing, School of Nursing, Applied Theology Institute, aline.d.castro@hotmail.com ${ }^{3}$ MNS, RN Coordinator of the Residency Training Program in Urgency and Emergency, Irmandade da Santa Casa de Misericordia de Sobral, micc2005@hotmail.com

${ }^{4}$ Nursing student, State University of the Valley of the Acarau, scholar at the Ceará State Foundation of Support for Scientific and Technological Development (FUNCAP), diogenezjunior@gmail.com

${ }^{5}$ RN Specialist in Surgical Nursing, Irmandade da Santa Casa de Misericordia de Sobral, alicequel.gomes@gmail.com

${ }^{6} \mathrm{PhD}$, Postdoctoral research fellow, Department of Health Systems Science, University of Illinois at Chicago, vanessaemille@gmail.com

Cómo citar este artículo en edición digital: Ponte Portela, A.C., Castro Olimpio, M.A., Vasconcelos Ponte, M.A., dos Santos, F.D., Gomes de Paiva, A.F., \& Carvalho de Sousa, V.E.

(2017). Percepción de los enfermeros sobre seguridad del paciente en el servicio de emergencia: un estudio cualitativo. Cultura de los Cuidados (Edición digital), 21(49). Recuperado de http://dx.doi.org/10.14198/cuid.2017.49.03

Correspondencia: Vanessa Sousa. 845 S Damen Ave, room 930, Chicago - IL - Estados Unidos - 60612. Teléfono: 1773 814-0517 Correo electrónico: vanessaemille@gmail.com Recibido: 20/01/2017; Aceptado: 10/05/2017

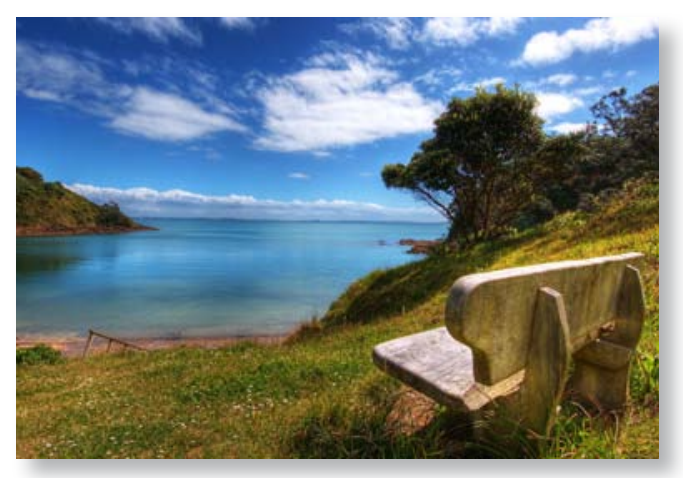

ABSTRACT

Nurses are in a key position to improve the quality of healthcare through patient safety interventions and strategies. However, there is a general misunderstanding of the effects of the numerous and complex work environment factors on patient safety. This qualitative study aims to explore nurses' perceptions of patient safety aspects in an emergency setting. Semistructured interviews were conducted with 13 Registered Nurses from an emergency ward in a large general hospital located in northeastern Brazil. Conventional content analysis in which analysis is gained without imposing preconceived categories was used to analyze the collected data. The findings were clustered in three main categories: Barriers and facilitators for the adoption of patient safety practices, Training on patient safety issues, and Nursing role on the quality of patient safety. Nurses reported that the factors influencing patient safety include: lack of resources, hospi- 
tal overcrowding, excessive workload, lack of training, and ineffective communication. Our results suggest that patient safety in the emergency wards could be improved by developing and reinforcing a safety culture and by providing the necessary infrastructure and support mechanisms.

Keywords: Risk management, patient safety, emergency nursing, qualitative research.

\section{RESUMEN}

Las enfermeras están en una posición clave en la mejora de la calidad de la atención a través de intervenciones y estrategias para la seguridad del paciente. En general, percepciones sobre el impacto de los factores del entorno de trabajo sobre seguridad de los pacientes son engañosas.

Este estudio cualitativo tuvo como objetivo explorar la percepción de enfermeras sobre seguridad del paciente. Las entrevistas semiestructuradas se llevaron a cabo con 13 enfermeras en una sala de emergencia en un hospital del noreste de Brasil. Un análisis de contenido convencional fue utilizado y el análisis se llevó a cabo sin imponer clases preconcebidas. Los resultados fueron agrupados en tres categorías: Barreras y facilitadores para la adopción de prácticas de seguridad del paciente, Problemas en la formación en seguridad del paciente y Papel de la enfermera en la calidad de las prácticas de seguridad del paciente. Las enfermeras informaron que los factores que afectan la seguridad del paciente incluyen: deficiencia de recursos, hacinamiento, sobrecarga de trabajo, mala formación y comunicación ineficaz. Los resultados sugieren que la seguridad de los pacientes se puede mejorar mediante el desarrollo y fortalecimiento de la cultura de seguridad y la provisión de infraestructura y mecanismos de apoyo.
Palabras clave: Gestión de riesgos, seguridad del paciente, enfermería de emergencia, investigación cualitativa.

\section{RESUMO}

Enfermeiras ocupam uma posição-chave na melhoria da qualidade da assistência por meio de intervenções e estratégias para a segurança do paciente. Em geral, percepções sobre o impacto dos inúmeros e complexos fatores do ambiente de trabalho sobre a segurança do paciente são equivocadas.

Este estudo qualitativo tem por objetivo explorar percepções de enfermeiras sobre a segurança do paciente no cenário de emergência. Entrevistas semiestruturadas foram conduzidas com 13 enfermeiras de uma unidade de emergência em um hospital localizado no nordeste do Brasil. Uma análise de conteúdo convencional, na qual a análise é executada sem impor categorias pré-concebidas, foi utilizada na análise dos dados. Os resultados foram agrupados em três categorias: Barreiras e facilitadores para a adoção de práticas de segurança do paciente, Problemas no treinamento em segurança do paciente e Papel da enfermeira na qualidade das práticas de segurança do paciente. Enfermeiras relataram que os fatores que afetam a segurança do paciente incluem: deficiência de recursos, superlotação, sobrecarga de trabalho, treinamento deficiente e comunicação não efetiva. Os resultados sugerem que a segurança do paciente nas unidades de emergência pode ser melhorada pelo desenvolvimento e reforço da cultura de segurança e pela provisão da infraestrutura e dos mecanismos de suporte necessários.

Palavras-chave: Gestão de riscos, segurança do paciente, enfermagem de emergência, pesquisa qualitativa. 


\section{INTRODUCTION}

Patient safety is a relatively new discipline in health care that focuses on preventing harm to patients. In the last years, the field of patient safety has received increased attention, especially after the publication of the Institute of Medicine report “To Err is Human”, which estimate that 44,000 to 98,000 people are harmed in the hospital each year (Kohn, Corrigan, \& Donaldson, 1999). A patient should never be harmed in the hospital due to medical errors while receiving care, and nurses are in an excellent position to advocate and create safe care environments (Hughes, 2008).

Patient safety indicators (PSIs) have been developed and used to provide information on potential in-hospital complications and adverse events following surgeries, procedures, and childbirth (Agency for Healthcare Research and Quality [AHRQ], 2016). The Agency for Healthcare Research and Quality (AHRQ) PSIs are divided in two categories: provider-level indicators (e.g. decubitus ulcer, accidental puncture, and foreign body left in during procedure) and area-level indicators (e.g. selected infections due to medical care, transfusion reaction, and postoperative hemorrhage) (AHRQ, 2016). Evidences have shown that nurses are in a key position to improve the quality of healthcare through patient safety interventions and strategies (Ghosh, Norton, \& Skiba, 2006; Mayo \& Duncan, 2004; Wild \& Bradley, 2005). However, lack of awareness and knowledge of nurses about patient safety strategies and indicators are existing barriers in many healthcare settings.

Emergency departments are locations that provide people access to emergency care 24 hours a day, 7 days a week. There is agreement that all emergency departments have a responsibility to deliver care that is evi- dently safe and of the highest possible quality (Ajeigbe, McNeese-Smith, Leach, \& Phillips, 2013). However, emergency departments have unique demands and problems like overcrowding, communication issues, increased risk of human errors, and healthcare worker shortages, which compromises patient safety (Eisenberg et al., 2005; Johnstone, 2007; Lambrou, Papastavrou, Merkouris, \& Middleton, 2015; Trzeciak \& Rivers, 2003). Moreover, only few studies have investigated the perceptions and/or knowledge of healthcare professionals about patient safety specifically on the ED (Ajeigbe et al., 2013; Lambrou et al., 2015).

There is a general misunderstanding of the effects of the numerous and complex work environment factors on patient safety. According to the AHRQ, understanding the complexity of the work environment and engaging in strategies to improve its effects is paramount to a high quality and safe care (Hughes, 2008). The objective of this study was to explore nurses' perceptions of patient safety aspects in an emergency setting.

\section{METHOD}

A qualitative study was conducted where data were collected through semi-structured interviews and analyzed by conventional content analysis. Interviews were carried out with Registered Nurses (RNs) who worked in the emergency department of a large general hospital located in northeastern Brazil. Nurses were invited to participate in the study in person and were interviewed after providing informed consent, on the date and time that was convenient for them.

An interview guide with a series of open and closed ended questions was used investigating the nurses' demographic and background variables, and perceptions about 


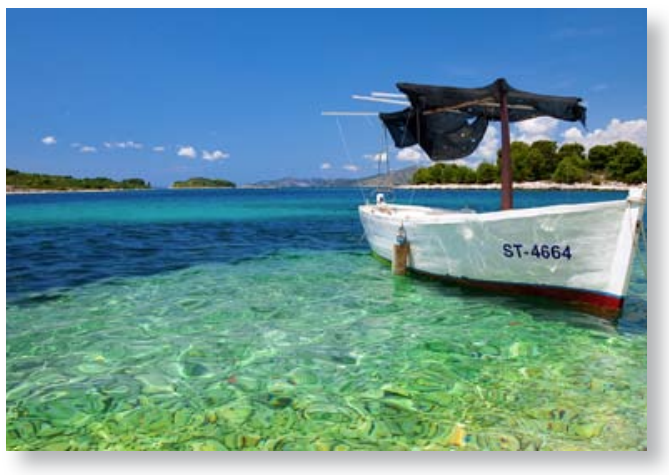

patient safety (strategies in use, barriers and facilitators, existence of training about patient safety, and suggestions for enhancing patient safety at their workplace). Thirteen nurses completed the study and saturation of responses was reached through all of the interviews. Institutional review board (IRB) approval was provided for the study.

\section{Data collection}

The data were collected in October and November 2015. Individual interviews were conducted with each nurse, lasting between 45 and 60 minutes each. One of the study authors carried out the interviews in a private room next to the emergency unit in which the nurses worked. The research interviewer was not acquainted with any of the nurses.

The interviews were audio taped, transcribed and analyzed using the conventional content analysis method. The interview guide focused on asking nurses about their perceptions of patient safety strategies, barriers and facilitators in their workplace, but allowed the researcher extend the scope of the interview with follow-up questions and probes, if necessary (e.g. 'describe what you mean by communication'). The interview guide also included questions about demographic and background variables of the nurses such as age, gender, academic degrees earned previ- ously, time since registration, time working in the emergency ward, and whether they were working in more than one job at a time.

\section{Data analysis}

The recordings of the interviews were transcribed verbatim and conventional content analysis was carried out, as proposed by Hsieh and Shannon (2005). Conventional content analysis is recommended for study designs that aims to describe a phenomenon, in this case the perceptions of nurses about patient safety aspects in their workplace. Compared with other types of content analysis (e.g. directed and summative), the conventional approach is more suitable when there is a lack of theory or research evidences on the topic under investigation (Hsieh \& Shannon, 2005).

The process began by the reading of the transcripts as many times as necessary, and flowed to the identification of thematic categories and names for the categories in an inductive manner. Different from other approaches, conventional content analysis is not based on preconceived categories, but the raw data is processed by open coding (Hsieh \& Shannon, 2005). Once the categories were identified, the authors discussed them and code categories with similar themes or concepts were collapsed. Finally, the authors coded the content of each statement within each category until consensus was reached.

\section{RESULTS}

\section{Sample characteristics}

Demographic and background information of the study sample is presented in Table 1. The final sample included 13 nurses. From them, 8 were female and 5 were male. More than $50 \%$ of subjects had Bachelor's degree 
only, the majority (85\%) had completed undergraduate studies in less than 5 years, and the majority (92\%) have been working in the emergency ward in less than 5 years. The majority of subjects (77\%) have reported working in more than one job at a time.

\section{Barriers and facilitators for the adoption of patient safety practices}

From the analysis of transcriptions, we explored nurses' perceptions of barriers and facilitators for the adoption of patient safety practices in their workplace. As the interviews progressed, it became evident that there were unique demands to the emergency ward that served as barriers for the adoption of safety practices by nurses.

Overcrowding and excessive workload were reported by some interviewees. One participant stated: "There is always a large demand of patients and too few nurses. I think all of us are overburdened." The problem with dimensioning was also noted in the comments of another participant: "A new dimensioning of nursing staff is urgent because this hospital receives so many patients and the number of professionals is not enough." As a direct consequence of inadequate dimensioning, nurses experience high workload: "Excessive workload is definitively one of the main barriers we have to deal with every day."

Deficient infrastructure was also identified

Table 1. Demographic and background characteristics of the sample.

\begin{tabular}{|c|c|c|}
\hline Variables & $\mathbf{n}$ & $\%$ \\
\hline \multicolumn{3}{|l|}{ Age groups } \\
\hline 20-34 years & 10 & 77.0 \\
\hline $35-49$ years & 2 & 15.3 \\
\hline 50-64 years & 1 & 7.7 \\
\hline \multicolumn{3}{|l|}{ Gender } \\
\hline Women & 8 & 61.5 \\
\hline Men & 5 & 38.5 \\
\hline \multicolumn{3}{|l|}{ Academic Degree } \\
\hline Bachelor $₫$ & 8 & 61.5 \\
\hline Post-bachelor nursing education & 5 & 38.5 \\
\hline 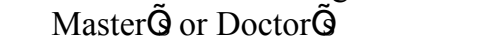 & 0 & - \\
\hline \multicolumn{3}{|l|}{ Time since registration } \\
\hline$<1$ year & 2 & 15.3 \\
\hline $1-2$ years & 3 & 23.0 \\
\hline $2-5$ years & 6 & 46.3 \\
\hline $5-10$ years & 1 & 7.7 \\
\hline$>10$ years & 1 & 7.7 \\
\hline \multicolumn{3}{|l|}{ Time working in the emergency ward } \\
\hline$<1$ year & 6 & 46.3 \\
\hline $1-2$ years & 3 & 23.0 \\
\hline $2-5$ years & 3 & 23.0 \\
\hline $5-10$ years & 0 & 0.0 \\
\hline$>10$ years & 1 & 7.7 \\
\hline \multicolumn{3}{|l|}{ Working in more than one job at a time } \\
\hline Yes & 10 & 77.0 \\
\hline No & 3 & 23.0 \\
\hline
\end{tabular}


by the nurses as a barrier to providing a safe care. Comments like "I think one of the main barriers to provide a safe care here is broken equipment", and "Deficient infrastructure and lack of materials make it difficult for us to ensure patient safety $100 \%$ of the time" attest the impact of lack of resources or poor infrastructure on patient safety.

A third barrier for providing a safe and efficient care is poor communication. When asked about what are the main barriers to patient safety in this emergency department, one of the nurses stated: "One of the main barriers to patient safety in this ward is poor communication within the team."

When asked about facilitators for patient safety, nurses listed safety measures such as patient identification, prevention of drug administration errors, proper documentation, and prevention of never events like hospital acquired pressure ulcers and falls. One nurse stated:

"Patient safety can be achieved by being aware of the patient identification before performing any procedure, having an effective communication with our colleagues and patients, being attentive during drug administration procedures, keeping medical records in a safe place, and being attentive to the risk for falls and pressure ulcers."

Another's comments also spoke to the importance of situation awareness for ensuring patient safety as she stated: "Paying attention to the patients' identification, using a risk classification system, and ensuring proper communication. I also believe that training on patient safety is very important."

One participant spoke of the importance of the relationship with the patient. She noted: "Patient safety requires more than just knowing regulations. The involvement between professionals and patients is as important as technical and theoretical knowledge, or leadership."

Another commented on how institutional contribute to patient safety stating, "I think patient safety requires an adequate number of human resources, proper support from hospital managers, and multi-professional cooperation."

\section{Training on patient safety issues}

Since some nurses reported that training is an important strategy to ensure patient safety, we asked them if they had ever participated in training about patient safety. One nurse stated: "No, I had never participated in such training, but I feel there is a need for it. A training about patient safety would be extremely beneficial for the whole care team... I need these skills."

In concordance, another commented: "I had received training a few times, I guess... The first time was when I started to work in this unit and received information on patient safety, and the second was in a training session provided in the hospital for all providers about risk prevention strategies."

\section{Nursing role on patient safety}

When nurses were asked about their role in promoting patient safety, the answers were varied. One nurse stated: "Patient safety is a team responsibility, but nurses play a central role in using the patient safety indicators and reporting systems, monitoring the client during the whole hospitalization, and using strategies to prevent errors and reduce the length of stay."

Other comments suggested that the participants view nursing role as having a high importance for patient safety: "I believe that nurses are responsible for raising awareness on patient safety in their workplace. We have to advocate for changes, for being attentive to risks during our shifts. We don't have to wait until the patient's conditions gets worse to take ac- 
tion to prevent complications. Simple things like hand sanitizing, changing decubitus positions, using protection equipment, paying attention to the patient identification, and having a good communication with the team can save lives."

It can be note that must nurses had knowledge of strategies and their role in patient safety, although they not always have sufficient time or resources to use that knowledge effectively. The importance of integrating the use of safety guidelines and holistic care was noted by one participant, "I think is our role to ensure that the safety guidelines are being followed without forgetting to provide holistic and comprehensive care."

Some nurses gave suggestions for making patient safety implementation more effective in their workplace. Comments like "I would suggest more frequent training sessions about patient safety, hiring more professionals, and improving the infrastructure of the emergency ward" and "Increasing the number of nursing professionals would definitively reduce the workload and the likelihood of errors" indicate that there is a need for investments in training, motivating and providing a system for patient safety in this hospital. One participant suggested: "It would be nice to have in-service education or a permanent system to prevent safety issues in the hospital, and especially in the emergency ward. This could be helpful in raising awareness of safety measures and getting providers engaged. People have to be reminded that they are dealing with people's lives, so they have to be more than careful."

\section{DISCUSSION}

The findings of this study describe opinions of nurses about patient safety aspects in an emergency unit. Overall, some common perceptions among all subjects were found.
The sample was predominantly young, hence most nurses had completed their Bachelor's education recently and were working in this ward for less than 5 years. The lack of experienced emergency nurses in hospitals has been recognized as a factor that impacts nursing education priorities.

One of the major priorities in emergency nursing education is medication safety and error prevention, which indicates that there is a need to get back to basics and ensure that emergency nurses are able to provide a safe care (Valdez, 2009). In addition, the increasing complexity of healthcare and adoption of new technologies requires that emergency nurses are able to use sound clinical judgment, and mentors or expert professionals are not usually available in the clinical setting to assist novice nurses in their tasks (Bisholt, 2012; Hezaveh \& Rafii, 2014).

It is apparent from the findings that there were difficulties encountered in providing a safe and efficient care, mostly related to overcrowding and excessive workload. Overcrowding is recognized as a threat for patient safety, hence emergency department overcrowding is considered a public health concern (Cowan \& Trzeciak, 2005; Trzeciak \& Rivers, 2003). One direct consequence of overcrowding is burden of the medical staff as demonstrated in this study, since many nurses reported burden due to inappropriate dimensioning of nursing staff and excessive demands in the ward.

Prior studies have identified burden of professionals as a key factor of compromised patient safety in the emergency department (Adriaenssens, De Gucht, Van Der Doef, \& Maes, 2011; Aiken et al., 2012; Boltz, Parke, Shuluk, Capezuti, \& Galvin, 2013), as well as in other medical units (Brown, Wickline, Ecoff, \& Glaser, 2009). Poor infrastructure 
also was reported by some nurses as a barrier to safe and effective care. Similarly, other studies reported that a reduction in infrastructure, capacity and leadership to support patient safety strategies in addition to technical difficulties led to reduced motivation of nurses to report adverse events in a maternity (Allen, Chiarella, \& Homer, 2010; Aveling, Kayonga, Nega, \& Dixon-Woods, 2015).

Nurses acknowledge the benefits of training for healthcare providers about patient safety, and suggested that training on this subject should occur more frequently. Studies have shown that educational programs have failed to prepare health professionals to adequately address patient safety (Institute of Medicine [IOM], 2003; VanGeest \& Cummins, 2003), which makes training on this subject so important.

In 2006, the American Association of Colleges of Nursing published the Hallmarks of Quality and Patient Safety in Baccalaureate Nursing Education, which includes competencies like critical thinking, communication, and ethics, the efficient use of healthcare systems and technologies, and the implementation of policies to enhance patient safety (American Association of Colleges of Nursing [AACN], 2006). However, our findings and those of others suggest that there are still many gaps to be filled to ensure that all patients reliably receive a safe care in the hospitals (Aiken et al., 2012; Aveling et al., 2015; Turunen, Partanen, Kvist, Miettinen, \& Vehvilainen-Julkunen, 2013).

When we asked nurses about their role in promoting patient safety, it was noted that the interviewees had knowledge about their role. Nurses viewed themselves as being in a central position to advocate for patient safety strategies, create a patient safety culture, and set patient safety as a priority in the workplace.

The AHRQ recognize that nurses are es- sential drivers of patient safety and quality improvement because their work is at the center of patient care and health assistance. Nurses' role in patient safety goes beyond implementing patient safety practices (e.g. using sterile barriers while performing procedures, preventing pressure ulcers, or evaluating patient understanding of plan and patient learning), but includes intercepting errors by others, as well as monitoring and surveilling hazards and patient deterioration before errors and adverse events occur (AHRQ, 2016).

Unfortunately, good will is not enough. If the service does not provide adequate resources and infrastructure for the professionals, they have to work under constant pressure conditions and mental workload. As a result, patient safety will be at risk or compromised (Aveling et al., 2015). This was demonstrated by the findings from the interviews, since improvements in the infrastructure, new dimensioning of the nursing staff, and hiring of more nurses were suggestions given several times by the subjects.

The findings of this study have some limitations. The small sample size of survey respondents makes it difficult to ensure that the results are representative in the study setting, although nurses' perceptions of patient safety aspects where similar. Due to the small sample size, it was not possible to run statistical analysis. Moreover, those nurses who were interested in participating in the study could have been the most aware or the most motivated to engage in patient safety strategies and their point of view can somehow be relate with that.

\section{CONCLUSIONS}

This study determined nurses' perceptions of barriers and facilitators for patient safety in the emergency department. In spite 
of the small sample size, the findings contribute to knowledge about this important issue and raise ideas for enhancing patient safety and integrating patient safety and quality improvement. The findings reveal that poor infrastructure and inappropriate dimensioning of nursing staff hindered patient, resulting in increased risk for patients and frustration of healthcare providers. Participants also recognized communication as a contributing factor to patient safety and agreed that bad communication between nurses, medical staff, patients, and careers are situations where patient harm is most likely to occur.

\section{REFERENCES}

- Adriaenssens, J., De Gucht, V., Van Der Doef, M., and Maes, S. (2011). Exploring the burden of emergency care: predictors of stress health outcomes in emergency nurses. Journal of Advanced Nursing, 67(6), 13171328. Available in http://dx.doi.org/10.1111/j.13652648.2010.05599.x

- Agency for Healthcare Research and Quality (2016). Patient Safety Indicators overview. Available in http://www. qualityindicators.ahrq.gov/modules/psi_overview.aspx

- Aiken, L.H., Sermeus, W., Van den Heede, K., Sloane, D.M., Busse, R., McKee, M., et al. (2012). Patient safety, satisfaction, and quality of hospital care: cross sectional surveys of nurses and patients in 12 countries in Europe and the United States. BMJ, 344, e1717. Available in http://dx.doi.org/10.1136/bmj.e1717

- Ajeigbe, D.O., McNeese-Smith, D., Leach, L.S., and Phillips, L.R. (2013). Nurse-physician teamwork in the emergency department: impact on perceptions of job environment, autonomy, and control over practice. Journal of Nursing Administration, 43(3), 142-148. Available in http://dx.doi.org/10.1097/NNA.0b013e318283dc23

- Allen, S., Chiarella, M., and Homer, C. S. (2010). Lessons learned from measuring safety culture: an Australian case study. Midwifery, 26(5), 497-503. Available in http://dx.doi.org/10.1016/j.midw.2010.07.002

- American Association of Colleges of Nursing (2006). Hallmarks of quality and patient safety: recommended baccalaureate competencies and curricular guidelines to ensure high-quality and safe patient care. Journal of Professional Nursing, 22(6), 329-330. Available in http:// dx.doi.org/10.1016/j.profnurs.2006.10.005

- Aveling, E.L., Kayonga, Y., Nega, A., and Dixon-Woods, M. (2015). Why is patient safety so hard in lowincome countries? A qualitative study of healthcare workers' views in two African hospitals. Globalization and Health, 11(1), 1-8. Available in http://dx.doi.org/10.1186/ s12992-015-0096-x

\section{Cultura de los ᄃuidados}

- Bisholt, B.K. (2012). The learning process of recently graduated nurses in professional situations - experiences of an introduction program. Nurse Education Today, 32(3), 289-293. Available in http://dx.doi.org/10.1016/j. nedt.2011.04.008

- Boltz, M., Parke, B., Shuluk, J., Capezuti, E., and Galvin, J. E. (2013). Care of the older adult in the emergency department: nurses' views of the pressing issues. The Gerontologist, 53, 441-453. Available in http://dx.doi. org/10.1093/geront/gnt004

- Brown, C.E., Wickline, M. A., Ecoff, L., and Glaser, D. (2009). Nursing practice, knowledge, attitudes and perceived barriers to evidence-based practice at an academic medical center. Journal of Advanced Nursing, 65(2), 371-381. Available in http://dx.doi.org/10.1111/ j.1365-2648.2008.04878.x

- Cowan, R.M. and Trzeciak, S. (2005). Clinical review: Emergency department overcrowding and the potential impact on the critically ill. Critical Care, 9(3), 291-295. Available in http://dx.doi.org/10.1186/cc2981

- Eisenberg, E.M., Murphy, A.G., Sutcliffe, K., Wears, R., Schenkel, S., Perry, S., and Vanderhoef, M. (2005). Communication in Emergency Medicine: Implications for $\mathrm{Pa}$ tient Safety. Communication Monographs, 72, 390-413. http://dx.doi.org/10.1080/03637750500322602

- Ghosh, T., Norton, M., and Skiba, D. (2006). Communication, coordination and knowledge sharing in the implementation of CPOE: impact on nursing practice. AMIA Annual Symposium Proceedings Archive, 928.

- Hezaveh, M.S. and Rafii, F. S.N. (2014). Novice nurses' experiences of unpreparedness at the beginning of the work. Global Journal of Health Science, 6(1), 215-222.

- Hsieh, H.F. and Shannon, S.E. (2005). Three approaches to qualitative content analysis. Qualitative Health Research, 15(9), 1277-1288. http://dx.doi. org/10.1177/1049732305276687

- Hughes, R.G.E. (2008). Patient safety and quality: An evidence-based handbook for nurses. Rockville:Agency for Healthcare Research and Quality.

- Institute of Medicine. (2003). Health professions education: A bridge to quality. National Academies Press, Washington.

- Johnstone, M.J. (2007). Patient safety ethics and human error management in ED contexts: Part I: Development of the global patient safety movement. Australasian Emergency Nursing Journal, 10(1), 13-20.

- Kohn, L.T., Corrigan, J.M., and Donaldson, M. S. (1999). To Err Is Human: Building a Safer Health System. Washington: The National Academies Press.

- Lambrou, P., Papastavrou, E., Merkouris, A., and Middleton, N. (2015). Professional environment and patient safety in emergency departments. International Emergency Nursing, 23(2), 150-155. Available in http://dx.doi. org/10.1016/j.ienj.2014.07.009

- Mayo, A.M. and Duncan, D. (2004). Nurse perceptions of medication errors: What we need to know for patient safety. Journal of Nursing Care Quality, 19(3), 209-217.

- Trzeciak, S. and Rivers, E.P. (2003). Emergency de- 
partment overcrowding in the United States: an emerging threat to patient safety and public health. Emergency Medicine Journal, 20(5), 402-405. Avalaible in http:// dx.doi.org/10.1136/emj.20.5.402

- Turunen, H., Partanen, P., Kvist, T., Miettinen, M., and Vehvilainen-Julkunen, K. (2013). Patient safety culture in acute care: a web-based survey of nurse managers' and registered nurses' views in four Finnish hospitals. International Journal of Nursing Practice, 19(6), 609-617. Available in http://dx.doi.org/10.1111/ijn.12112

- Valdez, A.M. (2009). So much to learn, so little time: educational priorities for the future of emergen- cy nursing. Advanced Emergency Nursing Journal, 31(4), 337-353. Available in http://dx.doi.org/10.1097/ TME.0b013e3181bcb571

- VanGeest, J.B. and Cummins, D.S. (2003). An educational needs assessment for improving patient safety: Results of a national study of physicians and nurses. National Patient Safety Foundation, Boston.

- Wild, D. and Bradley, E.H. (2005). The gap between nurses and residents in a community hospital's errorreporting system. Joint Commission Journal on Quality and Patient Safety, 31(1), 13-20.

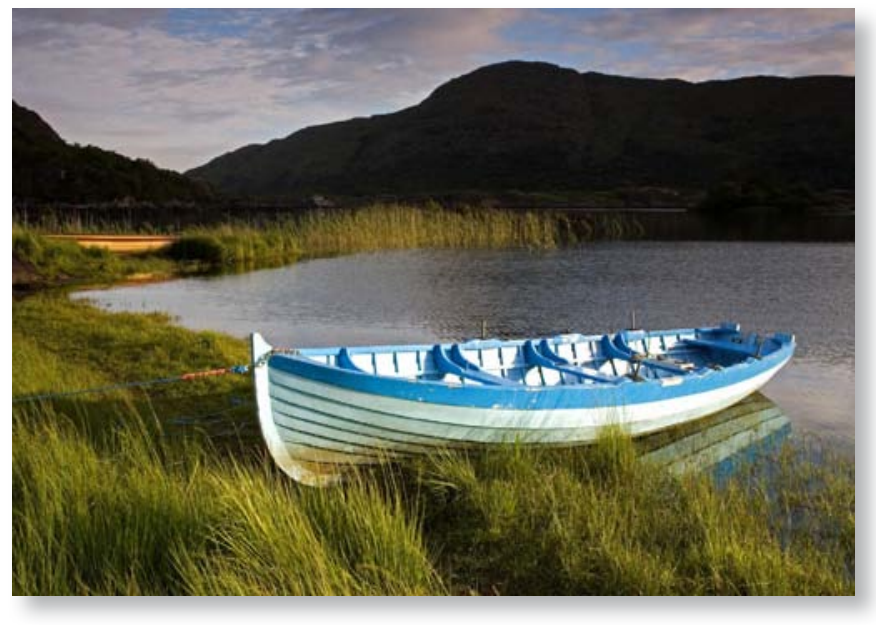

